\title{
EKSISTENSI BADAN USAHA MILIK DESA (BUMDes) SEBAGAI PENGGERAK EKONOMI DESA
}

\author{
Nining Asniar Ridzal ${ }^{1}$, Waode Adriani Hasan ${ }^{2}$ \\ ${ }^{1}$ Program Studi Akuntansi Universitas Muhammadiyah Buton \\ e-mail: nining.asniar@umbuton.ac.id
}

\begin{abstract}
Abstrak
Tujuan yang ingin dicapai dengan kegiatan pengabdian pada masyarakat ini melalui seminar adalah Memberikan Pemahaman bersama Kepada Masyarakat mengenai Pengelolaan BUMDes Sebagai Penggerak Ekonomi Desa sesuai dengan tujuan Pendirian BUMDes, Meningkatkan Pengetahuan Masyarakat Dalam Peningkatan Kesejahteraan serta Perekonomian Desa Melalui BUMDes.. Memberikan Gambaran tentang Faktor-Faktor Apa Saja Yang Menjadi Penghambat dalam pengelolaan BUMDes. Wujud nyata dari kegiatan pengabdian ini sebagai luarannya adalah Pemerintah Desa dan Masyarakat Khususnya Generasi Generasi Muda Mengelola BUMDes Sesuai dengan Tujuan Pendirian BUMDes dilakukan secara transparan dan professional, dan hasil lain adalah menerbitkan kegiatan ini ke Jurnal Nasional Terakreditasi.. Harapan kami sebagai tim pengabdian pada masyarakat hal ini dapat dilakukan secara berkesinambungan sebagai wujud Pengembangan Desa Bagi Pemerintah Desa dan Bentuk Pengabdian Masyarakat Melalui Pendampingan Oleh Pemateri Seminar.
\end{abstract}

Kata Kunci: Eksistensi, BUMDes, Ekonomi Desa

\section{A. Pendahuluan}

Sistem pemerintahan di Indonesia menganut asas desentralisasi. Undang-Undang No.23 Tahun 2014 Desentralisasi adalah penyerahan urusan pemerintahan oleh pemerintah pusat kepada daerah otonom berdasarkan asas otonomi. Tahun 2014 merupakan momentum kebangkitan penyelenggaraan pemerintahan desa. Berlakunya UU No.6 Tahun 2014 tentang desa memberikan semangat baru bagi desa untuk memprakarsai dirinya dengan melahirkan semangat "Desa Membangun", artinya desa ditempatkan sebagai tonggak awal keberhasilan pembangunan secara nasional. Sehingga penguatan desa tidak lepas dari kekuatan desa dalam penggalian potensi kearifan lokal dan semangat gotong royong warganya.

Desa menurut Peraturan Menteri Dalam Negeri Republik Indonesia Nomor 113 Tahun 2014 Desa adalah kesatuan masyarakat hukum yang memiliki batas wilayah yang berwenang untuk mengatur dan mengurus urusan pemerintahan, kepentingan masyarakat setempat berdasarkan prakarsa masyarakat, hak asal usul dan atau hak tradisional yang diakui 
dan dihormati dalam sistem pemerintahan Negara Kesatuan Republik Indonesia. Sehingga masyarakat desa memiliki hak yang sama untuk tumbuh dan berkembang mengikuti perubahan-perubahan baik dibidang ekonomi, politik, social dan budaya. Pembangunan sektor ekonomi dimasyarakat merupakan salah satu langkah dalam mencapai cita-cita nasional bangsa Indonesia yaitu memajukan kesejahteraan umum. Desa merupakan tonggak ekonomi suatu bangsa adalah cermin bahwa perekonomian masyarakat desa berhasil memberikan kesejahteraan bagi masyarakatnya.

Wujud implementasi sistem desentralisasi berupa otonomi desa yang termuat di dalam Undang-Undang Nomor 33 Tahun 2004 tentang Perimbangan Keuangan antara pemerintah pusat dan daerah, maka pemerintah pusat mengharapkan pemerintah Desa untuk lebih mandiri di dalam mengelola keuangan desanya. Untuk itu harus ada inisatif, peran aktif dan partisipasi aktif dari masyarakat desa itu sendiri untuk membangun dan mendirikan kelembagaan yang sistematis yang mampu memberikan peningkatan kesejahteraan bagi masyarakat desa. Bentuk Kelembagaan yang dimaksud adalah Badan Usaha Milik Desa (BUMDes) yang merupakan salah satu sumber PADes.

BUMDes adalah lembaga usaha yang dikelola oleh masyarakat dan pemerintahan desa dalam upaya memperkuat perekonomian desa dan dibentuk berdasarkan kebutuhan dan potensi desa (Handayati, 2009). BUMDes diharapkan dapat mengembangkan unit usaha dalam mendayagunakan potensi ekonomi.

Pembangunan BUMDes dimaksudkan sebagai upaya menampung seluruh kegiatan dibidang ekonomi dan/atau pelayanan umum yang dikelola oleh desa dan atau kerjasama antar desa. Menurut Abdul Rohman dkk (2018), Pendirian suatu BUMDes pada suatu desa bertujuan untuk:

a) Meningkatkan perekonomian desa

b) Mengoptimalkan aset desa agar bermanfaat untuk kesejahteraan desa

c) Meningkatkan usaha masyarakat dalam pengelolaan potensi ekonomi desa

d) Mengembangkan rencana kerja sama usaha antar desa dan/atau dengan pihak ketiga

e) Menciptakan peluang dan jaringan pasar yang mendukung kebutuhan layanan umum warga

f) Membuka lapangan kerja

g) Meningkatkan kesejahteraan masyarakat melalui perbaikan pelayanan umum, pertumbuhan dan pemerataan ekonomi desa, dan 
h) Meningkatkan pendapatan masyarakat desa dan Pendapatan Asli Desa

Beberapa hal yang menjadi penyebab gagalnya pengelolaan BUMDes, baik operasional maupun pengembangan bentuk usaha pada BUMDes, faktor utama adalah masih kurangnya sumber daya manusia yang mempunyai kemampuan, kurangnya sosialisasi dan pembelajaran, pendampingan dan fungsi pemerintah daerah dalam rencana pengembangan BUMDes, serta pemahaman masyarakat yang masih homogen sehingga mengakibatkan minimnya daya cipta masyarakat dalam mengembangkan potensi desa tersebut untuk dimanfaatkan dalam pembentukan unit usaha.

Langkomu merupakan salah satu wilayah desa administratif pada kecamatan Mawasangka Tengah, Kabupaten Buton Tengah, Sulawesi Tenggara (BPS. Kabupaten Buton, 2018). Desa langkomu telah membentuk BUMDes Yang Dinamai “Teluk Sejahtera". Pengabdian Pada Masyarakat ini Dilakukan di Desa langkomu didasarkan atas observasi Tim Pengusul Masih Perlu Di lakukan Pembinaan Pengelolaan BUMDes karena pada saat ini BUMDes belum di kelola dengan baik dalam artian BUMDes itu sendiri belum berjalan walaupun sudah di bentuk.

\section{B. Masalah}

Kita bersama masih mendapati desa yang memiliki BUMDes tetapi terkesan hanya papan nama dan mati suri. Kondisi ini karena adanya hambatan yang terjadi, dan kita perlu mengetahui hambatan apa saja yang dialami oleh BUMDes "Teluk Sejahtera", sehingga tidak dapat berjalan sesuai tujuan atau harapan. Berdasarkan hal tersebut maka kami merumuskan masalah sebagai berikut:

1. Bagaimana Memberikan Pemahaman bersama Kepada Masyarakat mengenai Pengelolaan BUMDes Sebagai Penggerak Ekonomi Desa sesuai dengan tujuan Pendirian BUMDes.

2. Bagaimana Meningkatkan Pengetahuan Masyarakat Dalam Meningkatkan Kesejahteraan serta Perekonomian Desa Melalui BUMDes..

3. Faktor-Faktor Apa Saja yang Menjadi Penghambat dalam pengelolaan BUMDes.

\section{Metode Pelaksanaan}

Sasaran dari kegiatan Pengabdian Pada Masyarakat ini adalah warga masyarakat di Desa Langkomu Kecamatan Mawasangka Tengah Kabupaten Buton Tengah yakni Perangkat Desa, Pengurus BUMdes, Ibu Ibu PKK, Karang Taruna sebanyak 40 (Empat Puluh) Orang. 
Luaran yang diharapkan dari kegiatan ini adalah: 1) Masyarakat Mengetahui Bagaimana Pengelolaan dan Manajemen BUMDes sebagai Penggerak Ekonomi Desa sesuai dengan tujuan didirikannya BUMDes. 2) Masyarakat Memahami Peran BUMDes dalam peningkatan kesejahteraan dan perekonimian desa.

Kegiatan pengabdian kepada masyarakat ini akan dilaksanakan di Desa Langkomu Kecamatan Mawasangka Tengah Kabupaten Buton Tengah. Pelaksanaan pengabdian kepada masyarakat ini dilakukan selama 1 (satu) bulan yang terdiri dari beberapa tahapan sebagai berikut:

1. Melakukan Pertemuan dengan Kepala Desa Langkomu Kecamatan Mawasangka tengah Kabupaten Buton Tengah guna menetapkan waktu pelaksanaan kegiatan serta izin untuk melaksanakan Kegiatan pengabdian Pada Masyarakat ini.

2. Menyiapkan Bahan Seminar yang akan dipaparkan.

3. Melaksanakan Kegiatan Seminar Melakukan Seminar dengan memberikan pengetahuan pada masyarakat tentang bagaimana pengelolaan atau bagaimana memanajemen BUMDes Demi Terwujudnya Desa Mandiri karena Mampu menggerakkan perekonomian di Desanya .

4. Metode Diskusi dengan masyarakat dan perangkat desa tentang faktor-faktor apa saja yang menjadi permasalahan dalam pengelolaan BUMDes di Desa Langkomu Kec.Mawasangka Tengah Kab. Buton Tengah.

\section{Pembahasan}

Kegiatan pengabdian ini terselenggara atas kerjasama dengan masyarakat Desa Langkomu Kecamatan Mawasangka Tengah Kabupaten Buton Tengah. Pelaksanaan Seminar ini merupakan salah satu tahapan penting dari kegiatan pengabdian kepada masyarakat sebagai bagian Caturdarma Perguruan Tinggi yang dilaksanakan pada tanggal 23 Maret 2020 mulai jam 10.00 WIB hingga selesai. Kegiatan Seminar dilakukan di Aula Balai Desa Langkomu Kecamatan Mawasangka Tengah Kabupaten Buton Tengah yang beralamat di Jalan Poros Mawasangka Dusun Pantai Baru. Yang memberi kata sambutan dalam kegiatan seminar ini adalah Desa Langkomu Kecamatan Mawasangka Tengah Kabupaten Buton Tengah. Dalam pelaksanaan kegiatan ini dihadiri oleh berbagai lapisan masyarakat. Tokoh masyarakat yang hadir antara lain Kepala Desa Masiri, Sekretaris Kepala Desa Masiri beserta seluruh RT dan RW, anggota karang taruna, pengelola BUMDes, serta Ibu-ibu PKK. 
Masyarakat yang hadir tampak sangat antusias mendengarkan pemaparan materi seminar yang disampaikan, hal ini tampak dari banyaknya masyarakat yang bertanya dan ingin mendapatkan penjelasan lebih mendalam bagaimana Peran Masyarakat Dalam Pengelolaan BUMDes Agar BUMDes yang ada tetap Eksis di Desa Langkomu. Dalam pengelolaan BUMDes saat ini sangat perlu untuk melibatkan generasi generasi muda, guna mengembangkan BUMDes yang Maju.

Sebagai wujud nyata dari kegiatan pengabdian ini sebagai luarannya adalah Pengelolaan BUMDes yang melibatkan masyarakat dilakukan secara transparan dan professional, dan hasil lain adalah menerbitkan kegiatan ini ke Jurnal Nasional Terakreditasi. Kegiatan Seminar dilakukan dengan metode ceramah dengan menggunakan media Laptop dan infocus, diskusi kepada masyarakat pedesaan. Kegiatan Seminar ini juga bermaksud untuk memotivasi masyarakat untuk turut serta dalam pengelolaan BUMDes sebagai penggerak ekonomi desa. Banyaknya potensi yang dimiliki Desa Langkomu antara lain : objek pariwisata, kepiting rajungan, jambu mete, rumput laut dapat dimanfaatkan guna pengembangan usaha di BUMDes, Yang mana potensi ini bisa dikembangkan bersama melalui BUMDes oleh Pemerintah Desa dan Masyarakat Secara Bersama-Sama sebagai upaya peningkatan kesejahteraan dan perekonomian masyarakat Desa Langkomu Kecamatan Mawasangka Tengah Kabupaten Buton tengah.. Materi seminar antara lain mengenai pemahaman apa yang dimaksud dengan BUMDes dan Bagaimana Mengelola BUMDes, Mengapa BUMDes diperlukan, mengapa perlu kelembagaan BUMDes, apa saja peranan BUMDes, apa tujuan pendirian BUMDes, BUMDes didirikan sesuai dengan kebutuhan dan potensi desa, dan bagaimana organisasi dan tata kepengurusan BUMDes. Dalam Kegiatan masyarakat sangat antusias dan memahami tentang materi yang dipaparkan dan ingin mengaplikasikannya di BUMdes Teluk Sejahtera Desa Langkomu. Namun untuk memperoleh hasil yang lebih maksimal kegiatan seperti ini atau sejenisnya harus selalu dilakukan sebagai kegiatan pendampingan masyarakat sehingga mereka mampu melakukan pengelolaan dan pemanfaatan BUMDes secara maksimal agar tercipta desa yang Mandiri dan Sejahtera Melalui BUMDes. 

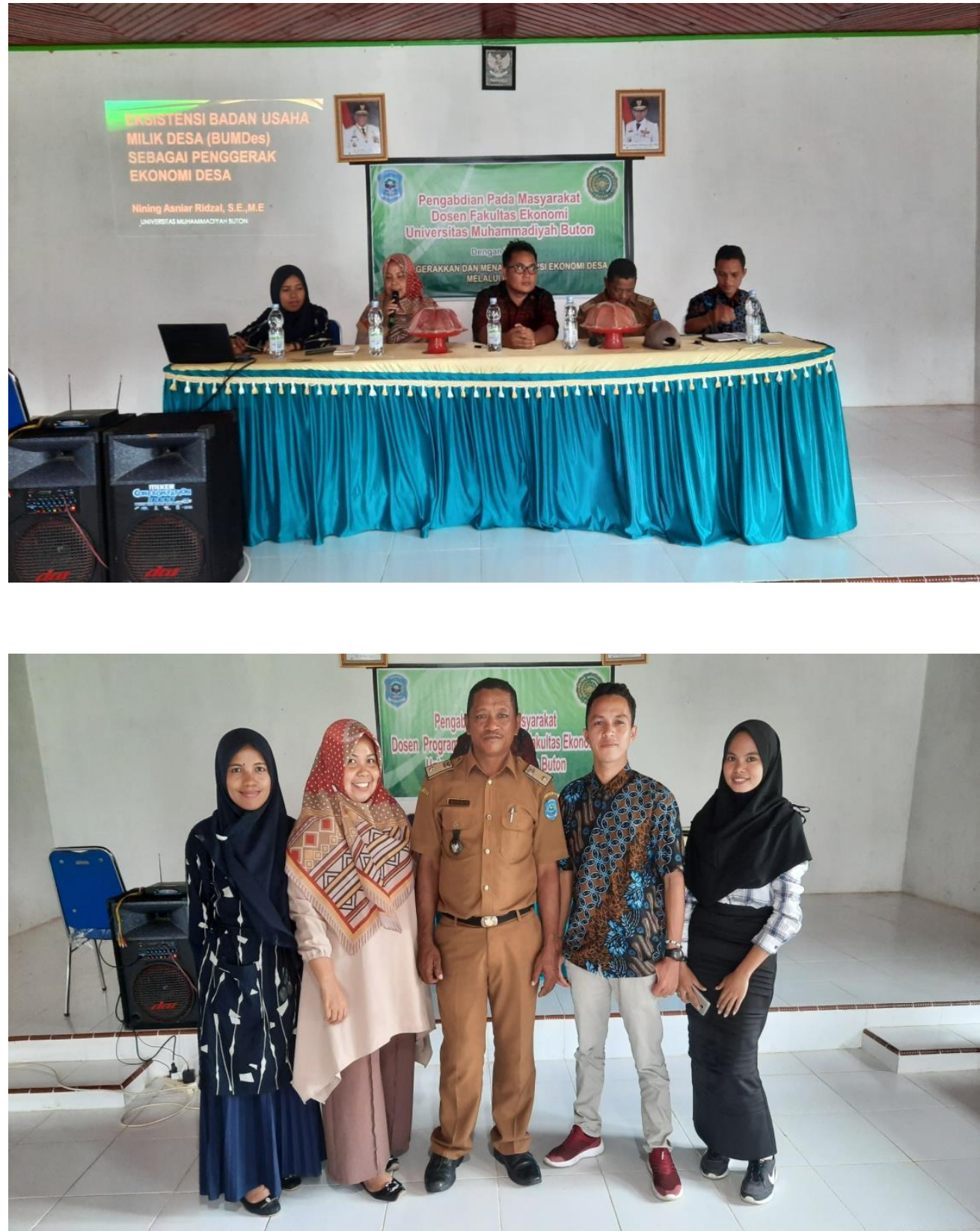

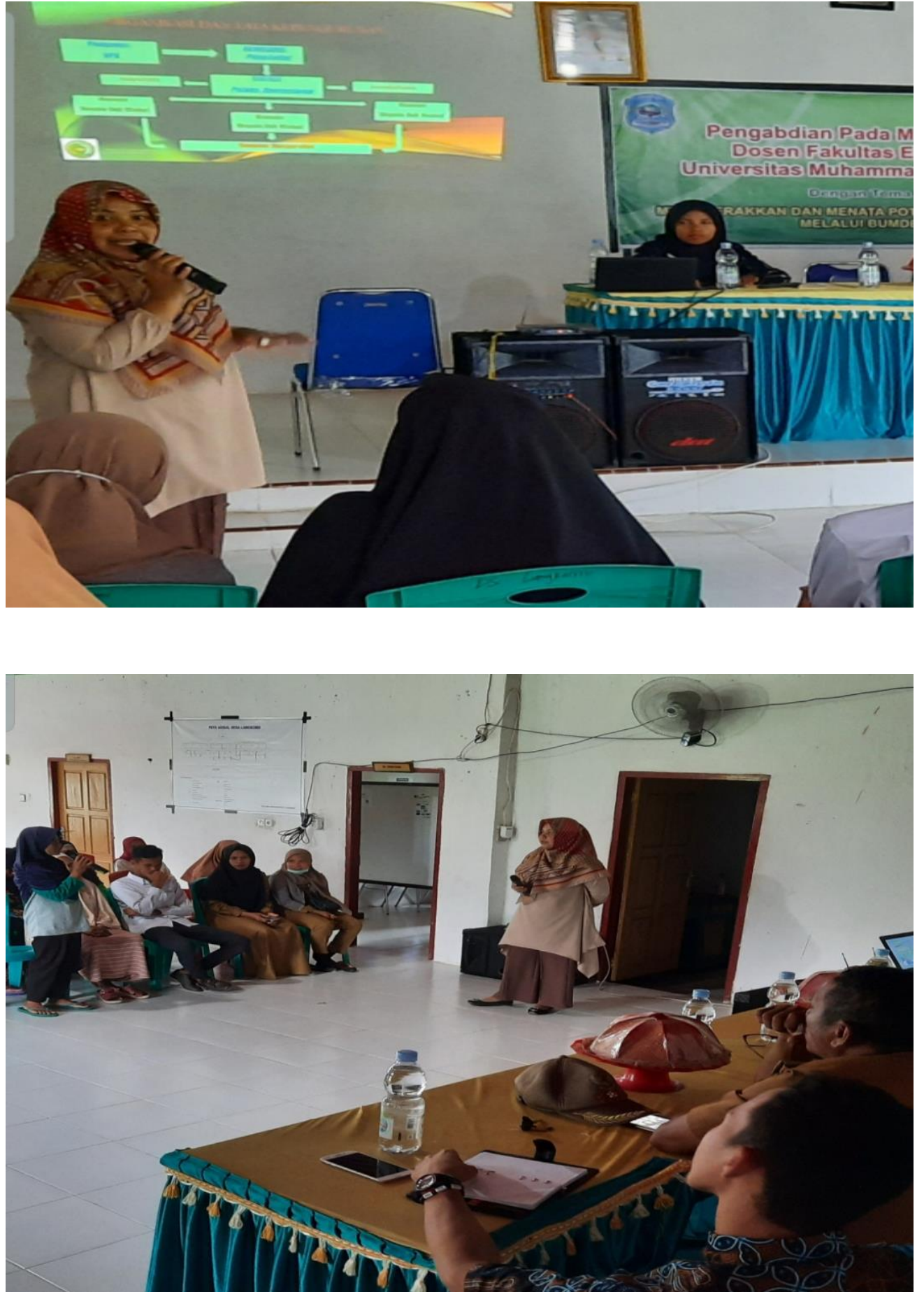


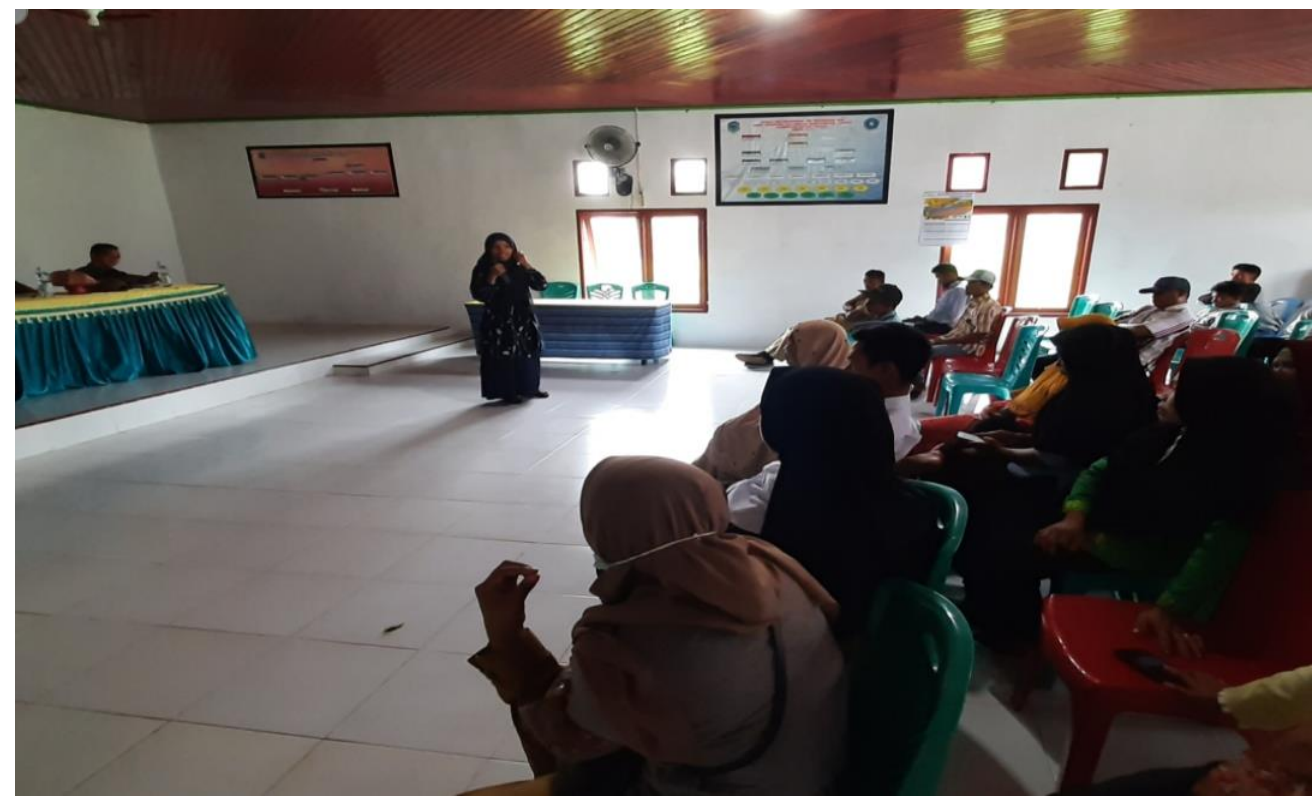

Gambar 1. Peserta Sosialisasi BUMDes

\section{E. Kesimpulan}

Kegiatan seminar Eksistensi Badan Usaha Milik Desa (BUMDes) sangat memberikan manfaat bagi masyarakat, masyarakat sangat bersemangat dalam diskusi dan berkeinginan untuk melakukan pengelolaan dan pengembangan BUMDEs Sesuai dengan tujuan pendirian BUMDes guna meningkatkan kesejahteraan masyarakat dan perekonomian Desa Langkomu agar menjadi Desa yang Mandiri dengan memanfaatkan potensi desa melalui BUMDes. Kegiatan seperti ini ataupun sejenisnya hendaknya dilakukan secara berkesinambungan sebagai wujud Pengembangan Desa Bagi Pemerintah Desa dan Bentuk Pengabdian Masyarakat Melalui Pendampingan Oleh Pemateri Seminar.

\section{DAFTAR PUSTAKA}

Abdul Rohman,dkk. (2018). Pengelolaan Administrasi Keuangan Pemerintah Desa Menuju Pengelolaan Keuangan Desa yang Tertib dan Akuntabel, Edisi Pertama. Yogyakarta: STIM YKPN.

Badan Pusat Statistik Kabupaten Buton. (2018). Kabupaten Buton Tengah Dalam Angka, Buton Tengah Regency in Figures. Katalog/catalog. 1102001.7414, ISSN: 26224461, BPS Kabupaten Buton: UD Syahid.

Handayati, P. (2009). Manajemen Badan Usaha Milik Desa. Malang: UM.Press. 
Peraturan Menteri Dalam Negeri Republik Indonesia Nomor 113 Tahun 2014 Tentang Pengelolaan Keuangan Desa

Undang-Undang Republik Indonesia Nomor 23 Tahun 2014 Tentang Pemerintahan Daerah

Undang-Undang Nomor 6 Tahun 2014 Tentang Desa

Undang-Undang Republik Indonesia Nomor 33 tahun 2004 Tentang Perimbangan Keuangan antara pemerintah Pusat dan Daerah 